\title{
High Education Level Protects European Americans But Not African Americans Against Chronic Obstructive Pulmonary Disease: National Health Interview Survey
}

\author{
Shervin Assari ${ }^{1}$, Hamid Chalian ${ }^{2}$, Mohsen Bazargan ${ }^{1,3}$ \\ ${ }^{1}$ Department of Family Medicine, Charles R Drew University of Medicine and Science, Los Angeles, USA \\ ${ }^{2}$ Department of Radiology, Duke University Medical Center, Durham, USA \\ ${ }^{3}$ Department of Family Medicine, UCLA, Los Angeles, USA
}

Email address:

assari@umich.edu (S. Assari)

\section{To cite this article:}

Shervin Assari, Hamid Chalian, Mohsen Bazargan. High Education Level Protects European Americans But Not African Americans Against Chronic Obstructive Pulmonary Disease: National Health Interview Survey. International Journal of Biomedical Engineering and Clinical Science. Vol. 5, No. 2, 2019, pp. 16-23. doi: 10.11648/j.ijbecs.20190502.12

Received: August 23, 2019; Accepted: September 6, 2019; Published: September 24, 2019

\begin{abstract}
Background: Education level reduces the risk of chronic diseases (CDs), including Chronic Obstructive Pulmonary Disease (COPD). Minorities' Diminished Returns, however, refer to smaller health benefits of socioeconomic position (SEP) improvement for racial and ethnic minorities compared to majority groups. It is not known if MDRs exist for the effects of education level on COPD for African Americans (AAs), relative to European Americans (EAs). Aims: Using a nationally representative sample, the current study explored racial and ethnic variation in the association between education level and COPD among American adults. Methods: Data came from the National Health Interview Survey (NHIS 2015), a national survey. A total of 25,488 adults (18+ years old) were included in the study. From this number, 4,533 (17.8\%) were AAs and 20,955 $(82.2 \%)$ were EAs. Education level was the independent variable. COPD was the outcome. Age, gender, and income were the covariates. Race/ethnicity was the moderator. Results: Overall, education level was inversely associated with the odds of COPD. A statistically significant interaction was found between race/ethnicity and education level on odds of COPD, indicating smaller effect of education for AAs compared to EAs. Conclusions: In line with the Minorities' Diminished Returns (MDRs), highly educated AAs remained at high risk for COPD, a pattern which is not observed for EAs. Policies that exclusively address racial/ethnic inequalities in SEP may not be enough for eliminating racial/ethnic inequalities in COPD in the US. Public policies must go beyond equalizing SEP and address structural and environmental barriers that disproportionately increase risk of COPD in AAs across SEP levels. Future research should test if residential segregation and exposure to air pollutants contributes to high prevalence of COPD in highly educated AAs. Research is needed on multi-level interventions that may minimize MDR-related health disparities.
\end{abstract}

Keywords: Socioeconomic Position, Socioeconomic Status, Educational Attainment, Ethnicity, Race, Ethnic Groups, African Americans, Blacks, COPD, Chronic Obstructive Pulmonary Disease

\section{Introduction}

Although socioeconomic position (SEP) is amongst the strongest determinants of health [1-8], such effect is unequal across racial/ethnic groups $[9,10]$. While high education level predicts better health $[11,12]$, and low education level strongly predicts worse health [13], these effects are not identical across various social groups. As such, Minorities' Diminished Returns (MDRs) refer to smaller health effects of
SEP indicators particularly education level in the members of racial and ethnic minorities particularly African Americans (AAs), relative to European Americans (EAs), as an overlooked mechanism behind racial and ethnic inequalities in health $[9,10]$.

Considerable MDRs [9], defined as relative disadvantage of racial and ethnic groups in receiving health gain from SEP resources, are shown for many health outcomes [10]. Supporting this framework [9, 10], SEP indicators such as 
education level are shown to have stronger effects on drinking [14], depression [15], suicide [16], chronic disease (CDs) [15], and mortality [17-20] for EA than AA individuals.

Some of the mechanisms behind the MDRs include societal and structural processes and factors such as residential segregation, extra costs of moving upward in society [21, 22], and higher level of exposure and sensitivity to discrimination [23] in non-EAs (particularly AAs). As a result of such societal processes, high SEP tends to produce less tangible health effects for AA than EA people. However, less is known about MDRs of education level for COPD.

As a result of MDRs [9, 10], the health effects of SEP indicators such as education level [25-27] are diminished for racial and ethnic minority groups [9, 10, 28, 95-97]. Thus, diverse racial and ethnic groups not only vary in their SEP but also how their SEP turns to health outcomes [23, 29, 30]. Although high education level means less exposure to risks overall [25-27], social groups with the same level of education level have unequal life experience [21, 22, 31]. That is, the very same SEP indicator, such as education level, shows a smaller impact of the purchasing power for the racial/ethnic minority groups, compared to the majority group [32-35]. For example, high education level gives less access to goods and services, quality of residential places, job quality, and health to AAs than EAs [37, 25-27, 36]. As the US society tends to treat individuals based on their race/ethnicity, heritage, and skin color, high SEP generates fewer opportunities for AAs than EAs [38, 39]. AAs face more problems and barriers to leverage and built on their available material resources, human capital, and psychological assets $[38,39]$. As a result of MDRS [9, 10], we observe worse than expected health effects in high SEP and highly educated AAs, when compared to EA people [29, 43].

Aims

To better understand whether MDRs also apply to racial/ethnic disparities in COPD, we compared AA and EA people for the negative effect of education level on COPD. Although research has well-documented the effects of race/ethnicity [101] and SEP (education level) [102] on COPD, very few studies have ever tested MDRs of SEP on COPD. Such study would require studying the non-additive effects of race/ethnicity, and SEP on COPD. So, it is still not fully known whether it is whether race/ethnicity and SEP or race/ethnicity or SEP that cause COPD disparities [83]. To produce generalizable results, we used data from the National Health Interview Survey (NHIS 2015), a study with a nationally representative sample of adults (18+ years old). As suggested by the MDRs [9], we expected smaller effect of SEP (education level) on COPD for AAs than EAs.

\section{Materials and Methods}

\section{Design and Setting}

This cross-sectional study borrowed data from the NHIS 2015, a national health survey of American adults sponsored by the Centers for Disease Control and Prevention (CDC). The NHIS is a landmark health survey that produces national prevalence estimates for a wide range of health indicators [103]. The data collection is done by the National Center for Health Statistics (NCHS), CDC.

The sample is limited to the civilians, non-institutionalized, adults, who were residing in the United States. The NHIS data collection is conducted in a continuous manner throughout each year. The sample design follows a multistage probability sample that recruited a representative sample of households and non-institutional people.

The NHIS sampling and sample design is described elsewhere. NHIS uses a multi-stage sampling strategy that involves survey weights. The first stage of the current multi-stage sample design was sampling 428 primary sampling units (PSUs) drawn from 1,900 PSUs, with all the 50 US states and the District of Columbia have representative PSUs in the study. A PSU may be either a county, some small counties, or a metropolitan statistical area.

\section{Sample and Sampling}

The NHIS sampling cores consist of the following components: (1) the Household Composition section, (2) the Family Core, (3) the Sample Child Core, and (4) the Sample Adult Core. The U.S. Census Bureau acts as the data collection agent for the NHIS, under a contractual agreement between the two organizations. The NHIS interviews were face-to face, however, they could rarely occur in the participants' households. This interview is sometimes followed with a telephone interview. 28932 adults enter this analysis.

\section{Ethics}

The NHIS study ethics was approved by the CDC's Institutional Review Board (IRB). All participants provided informed written consent. All the data were collected, stored, and analyzed without any identifier [48].

Measures

\section{Independent Variable}

Education level (EA). Education level was operationalized as an interval (continuous) variable with a range between 0 and 21. Participants were asked about the number of years of schooling. Higher scores reflect higher education level (number of schooling).

\section{Moderator}

Race/Ethnicity. All participants self-identified their race/ethnicity. Race/ethnicity was treated as a categorical variable in the current study [AAs $=1, \mathrm{EAs}=0]$. All AAs and EAs in this study were non-Hispanic Blacks.

\section{Covariates}

Sociodemographic characteristics in the current study included gender, age, region, and income. Age was a continuous measure. Gender was dichotomous (male1, female 0 ). Region was a nominal variable with the following four levels: (1) Northeast, (2) Midwest, (3) South, and (4) West. West was the reference category. Income was measured as annual last year income, which was operationalized as a 11-level continuous measure.

\section{Outcome}

Chronic Obstructive Pulmonary Disease (COPD). The following item was used to measure the lifetime history of 
COPD. Participants were asked, "Have you EVER been told by a doctor or other health professional that you had chronic obstructive pulmonary disease, also called COPD"?

Data Analysis

We used survey mode of the SPSS 23.0 (IBM Inc, NY, USA) to analyze the NHIS-2015 data. Taylor series linearization was used to re-calculate the standard errors (SEs) that address complex design of the NHIS sample. As a result, our estimates are generalizable to the US sample [44-46]. To describe our sample, we reported $\mathrm{n}$ and $\%$. We ran four logistic regression models for our multivariable modeling, both $\mathrm{t}$ in the pooled sample. Model 1 had the main effects of race/ethnicity, education level, and covariates. Model 2 also included the following interaction terms: race/ethnicity $\times$ education level. Model 3 was performed in EAs. Model 4 was performed in AAs. In all models, education level was the independent variable (IV), COPD was the dependent variable (DV), and age, gender, region, marital status, employment, and income were covariates. Race/ethnicity was the moderator.

\section{Results}

\subsection{Descriptive Data}

This analysis included 25488 adults (18+ years old). From this number, 4,533 (17.8\%) were AAs and 20,955 (82.2\%) were EAs. Table 1 presents the summary of descriptive characteristics of the overall sample and by race/ethnicity. $4.6 \%$ had COPD. $17.5 \%$ were current smokers. As this table shows, from all participants, $55.2 \%$ were women, $27.8 \%$ were AA, and $82.2 \%$ were EA.

Table 1. Descriptive statistics $(n=25488)$.

\begin{tabular}{|c|c|c|c|c|c|c|}
\hline Characteristics & Mean & SD & Mean & SD & Mean & SD \\
\hline Age & 51.73 & 18.39 & 52.29 & 18.47 & 49.14 & 17.78 \\
\hline Education & 15.48 & 2.82 & 15.66 & 2.73 & 14.65 & 3.08 \\
\hline \multirow[t]{2}{*}{ Income * } & 6.70 & 3.10 & 6.83 & 3.12 & 5.87 & 2.86 \\
\hline & $\mathrm{n}$ & $\%$ & $\mathrm{n}$ & $\%$ & $\mathrm{n}$ & $\%$ \\
\hline \multicolumn{7}{|l|}{ Gender* } \\
\hline Female & 14072 & 55.2 & 11311 & 54.0 & 2761 & 60.9 \\
\hline Male & 11416 & 44.8 & 9644 & 46.0 & 1772 & 39.1 \\
\hline \multicolumn{7}{|l|}{ Region* } \\
\hline Northeast & 4395 & 17.2 & 3769 & 18.0 & 626 & 13.8 \\
\hline Midwest & 6262 & 24.6 & 5492 & 26.2 & 770 & 17.0 \\
\hline South & 9118 & 35.8 & 6385 & 30.5 & 2733 & 60.3 \\
\hline West & 5713 & 22.4 & 5309 & 25.3 & 404 & 8.9 \\
\hline \multicolumn{7}{|l|}{ Employed } \\
\hline No & 11803 & 46.3 & 9586 & 45.7 & 2217 & 48.9 \\
\hline Yes & 13685 & 53.7 & 11369 & 54.3 & 2316 & 51.1 \\
\hline \multicolumn{7}{|l|}{ Married* } \\
\hline No & 14419 & 56.6 & 11014 & 52.6 & 3405 & 75.1 \\
\hline Yes & 11069 & 43.4 & 9941 & 47.4 & 1128 & 24.9 \\
\hline \multicolumn{7}{|l|}{ Current Smoking } \\
\hline No & 21024 & 82.5 & 17303 & 82.6 & 3721 & 82.1 \\
\hline Yes & 4464 & 17.5 & 3652 & 17.4 & 812 & 17.9 \\
\hline \multicolumn{7}{|l|}{ COPD } \\
\hline No & 24320 & 95.4 & 19927 & 95.1 & 4393 & 96.9 \\
\hline Yes & 1168 & 4.6 & 1028 & 4.9 & 140 & 3.1 \\
\hline
\end{tabular}

* $p<0.05$, Chronic Obstructive Pulmonary Disease (COPD), African American (AA), standard Deviation (SD)

\subsection{Logistic Regressions}

Table 2 summarizes the results of two nested logistic regressions. Model 1 was without interactions (Model 1). Model 2, however had two interactions. Model 1 showed that overall, higher education level is associated with lower odds of COPD. Model 2 showed significant interactions between the effects of race/ethnicity and education level on odds of COPD, suggesting that the negative effect of education level on odds of COPD is smaller for AAs compared to EAs (Table 2).

Table 2. Pooled sample logistic regressions.

\begin{tabular}{lcccccc}
\hline & B & SE & OR & $\mathbf{9 5 \%}$ CI & & p \\
\hline Model 1 (Main Effects) & & & & & \\
Race / & -0.63 & 0.10 & 0.53 & 0.44 & 0.64 & .000 \\
Ethnicity (AA) & & & & & \\
Gender (male) & 0.07 & 0.06 & 1.07 & 0.95 & 1.22 & .272 \\
Region & & & & & & \\
West & 1.00 & & & & & \\
Northeast & -0.10 & 0.11 & 0.91 & 0.74 & 1.11 & .353 \\
Midwest & 0.07 & 0.09 & 1.07 & 0.90 & 1.29 & .439 \\
South & 0.15 & 0.09 & 1.16 & 0.98 & 1.38 & .089 \\
Smoker & 1.49 & 0.07 & 4.44 & 3.85 & 5.11 & .000 \\
Age & 0.04 & 0.00 & 1.04 & 1.03 & 1.04 & .000 \\
Married & -0.01 & 0.07 & 0.99 & 0.87 & 1.13 & .928 \\
Employed & -1.30 & 0.09 & 0.27 & 0.23 & 0.33 & .000 \\
Education & -0.10 & 0.01 & 0.91 & 0.89 & 0.93 & .000 \\
Constant & -3.85 & 0.24 & 0.02 & & & .000 \\
Model 2 (Main Effects + Interactions) & & & & \\
Race / & -2.20 & 0.40 & 0.00 & 0.11 & 0.05 & 0.24 \\
Ethnicity (AA) & & & & & & \\
Gender (male) & 0.07 & 0.06 & 0.25 & 1.08 & 0.95 & 1.22 \\
Region & & & & & & \\
West & 1.00 & & & & & \\
Northeast & -0.10 & 0.11 & 0.33 & 0.90 & 0.73 & 1.11 \\
Midwest & 0.06 & 0.09 & 0.52 & 1.06 & 0.88 & 1.28 \\
South & 0.14 & 0.09 & 0.10 & 1.15 & 0.97 & 1.37 \\
Smoker & 1.48 & 0.07 & 0.00 & 4.40 & 3.82 & 5.07 \\
Age & 0.04 & 0.00 & 0.00 & 1.04 & 1.03 & 1.04 \\
Married & 0.00 & 0.07 & 0.95 & 1.00 & 0.87 & 1.14 \\
Employed & -1.30 & 0.09 & 0.00 & 0.27 & 0.23 & 0.33 \\
Education & -0.11 & 0.01 & 0.00 & 0.89 & 0.87 & 0.91 \\
Education * & 0.12 & 0.03 & 0.00 & 1.12 & 1.06 & 1.19 \\
Constant & -3.61 & 0.25 & 0.00 & 0.03 & & \\
\hline A & & & & & & \\
\hline
\end{tabular}

Outcome: Chronic Obstructive Pulmonary Disease (COPD), African American (AA), Confidence Interval (CI).

Table 3 summarizes the results of two identical ethnic-specific logistic regression models. Model 3 was in EAs and Model 4 was in AAs. Model 3 showed that higher education level is associated with lower odds of COPD for EAs. Model 4, however, did not show any effect of educational level and odds of COPD. This suggests a negative effect of education level for EAs but not AAs (Table 3). 
Table 3. Ethnic-specific logistic regressions.

\begin{tabular}{lllllll}
\hline & B & SE & OR & $\mathbf{9 5 \%}$ CI & p \\
\hline Model 3 (EAs) & & & & & & \\
Gender (Male) & 0.09 & 0.07 & 1.09 & 0.95 & 1.25 & .203 \\
Region & & & & & & \\
West & 1.00 & & & & & \\
Northeast & -0.12 & 0.11 & 0.88 & 0.71 & 1.09 & .256 \\
Midwest & 0.04 & 0.10 & 1.04 & 0.86 & 1.26 & .697 \\
South & 0.14 & 0.09 & 1.15 & 0.96 & 1.38 & .118 \\
Smoker & 1.56 & 0.08 & 4.75 & 4.07 & 5.54 & .000 \\
Age & 0.04 & 0.00 & 1.04 & 1.03 & 1.04 & .000 \\
Married & -0.05 & 0.07 & 0.95 & 0.83 & 1.10 & .502 \\
Employed & -1.29 & 0.10 & 0.27 & 0.23 & 0.33 & .000 \\
Education & -0.11 & 0.01 & 0.89 & 0.88 & 0.91 & .000 \\
Constant & -3.67 & 0.26 & 0.03 & & & .000 \\
Model 4 (AAs) & & & & & & \\
Gender (Male) & -0.02 & 0.18 & 0.98 & 0.68 & 1.40 & .901 \\
Region & & & & & & \\
West & 1.00 & & & & & \\
Northeast & 0.21 & 0.43 & 1.23 & 0.53 & 2.83 & .626 \\
Midwest & 0.43 & 0.40 & 1.54 & 0.71 & 3.35 & .279 \\
South & 0.30 & 0.36 & 1.35 & 0.66 & 2.74 & .409 \\
Smoker & 1.01 & 0.20 & 2.76 & 1.88 & 4.05 & .000 \\
Age & 0.04 & 0.01 & 1.04 & 1.03 & 1.05 & .000 \\
Married & 0.41 & 0.20 & 1.50 & 1.01 & 2.23 & .043 \\
Employed & -1.41 & 0.28 & 0.24 & 0.14 & 0.42 & .000 \\
Education & -0.01 & 0.03 & 0.99 & 0.94 & 1.05 & .815 \\
Constant & -5.72 & 0.69 & 0.00 & & & .000 \\
\hline
\end{tabular}

Outcome: Chronic Obstructive Pulmonary Disease (COPD), African American (AA), Confidence Interval (CI).

\section{Discussion}

Two findings were observed. First, education level was inversely associated with the prevalence of COPD in the overall sample. Second, AAs were at a relative disadvantage in comparison to EAs regarding the protective effect of education level on COPD. That is, the negative association between SEP (i.e., education level) an COPD was weaker for AAs than EAs. As a result, highly educated AAs remain at high risk of COPD, compared to highly educated EAs.

The first finding on the inverse association between education level and COPD reflects protective effect of SEP against COPD. Protective effect of SEP, particularly education level, is well established in the epidemiology [78] and economics [77] literatures. Prevalence of CDs is higher in low SEP sections of the society [77]. Some evidence suggests that CD gap mediates the mortality gap in race/ethnicity and SEP [104].

The second finding that the very same SEP indicator (education level) showed a considerably stronger impact on prevalence of COPD for EAs than AAs is not new. In one study, education better reduced blood pressure of non-Hispanics than Hispanics [105]. In another study, education better reduced disability for Whites than Blacks. Similar to the patterns seen for blood pressure, the effects of SEP on overall health, obesity, impulsivity, and smoking, and drinking are larger for EAs than AAs [56, 58, 93]. These patterns are robust as shown for children [107-110], adults [15, 16] and older adults $[29,37]$.

One of the mechanisms of the MDRs is that high education level has a smaller effect on reducing the risk of poverty for AAs, compared to EAs $[57,94]$. Another mechanism is that high SEP AAs face more not less discrimination [111-117].

Researchers should also consider that health disparities research may require study of multiplicative effects of race/ethnicity and SEP. This is because race/ethnicity and SEP, but not race/ethnicity or SEP, cause disparities.

\section{Limitations}

Every study has some limitations. To list a few methodological limitations, we can refer to the cross-sectional design that limits any causal conclusions. It is, however, unlikely that COPD causes low SEP. Still, CDs may result in downward social mobility [70 73]. This study measured COPD with a self-reported rather than measured or administered data. Although self-reported COPD is valid [54, 55], future research may test if these results can be replicated using other SEP indicators, other racial and ethnic groups, and using comprehensive measures. The study is at risk of omitted confounders.

\section{Conclusions}

In the United States, the inverse association between education level and COPD is weaker for AAs than EAs. As a result, we observe more COPD in highly educated AAs compared to highly educated EAs. Public and social policy solutions should go beyond equalizing SEP and specifically address structural causes of MDRs of SEP. Such MDRs are historically and systemically overlooked contributor to racial and ethnic health disparities in the US.

\section{Authors' Contributions}

S. A. designed and performed the approved the revisions and confirmed the final version. H. C. and M. B. contributed to the drafts and revision.

\section{Funding}

Assari and Bazargan are supported by grants from the Center for Medicare and Medicaid Services (CMS; H0CMS331621 and National Institute of Health (NIH, U54MD008149, R25 MD007610, U54MD007598 and U54 TR001627). Shervin Assari is also partly supported by the NIH grants CA201415-02, U54CA229974, and U54CA229974.

\section{Acknowledgements}

We acknowledge the contributions made by Hamid Helmi.

\section{Conflicts of Interest}

Authors declare no conflicts of interest.

\section{References}

[1] American Lung Association (ALA). Socioeconomic and Racial Asthma Disparities in Asthma. Available online: www.lung.org/local-content/illinois/documents/socioeconomic -asthma-disparities.pdf (accessed on 1st 05 2019). 
[2] Mirowsky, J.; Ross, C. E. Education, Social Status, and Health. Aldine de Gruyter: New York, NY, USA, 2003.

[3] Bowen, M. E.; González, H. M. Childhood socioeconomic position and disability in later life: results of the health and retirement study. Am. J. Public Health 2010, 100, S197-S203.

[4] Herd, P.; Goesling, B.; House, J. S. Socioeconomic position and health: the differential effects of education versus income on the onset versus progression of health problems. J. Health Soc. Behav. 2007, 48, 223-238.

[5] Kim, J. Intercohort trends in the relationship between education and health: examining physical impairment and depressive symptomatology. J. Aging Health. 2008, 20, 671-693. doi: 10.1177/0898264308321004.

[6] Marmot M, Allen JJ. Social determinants of health equity. Am J Public Health. 2014 Sep; 104 Suppl 4: S517-9. doi: 10.2105/AJPH.2014.302200.

[7] Leopold, L.; Engelhardt, H. Education and physical health trajectories in old age. Evidence from the Survey of Health, Ageing and Retirement in Europe (SHARE). Int. J. Public Health 2013, 58, 23-31.

[8] Johnson-Lawrence, V. D.; Griffith, D. M.; Watkins, D. C. The effects of race, ethnicity and mood/anxiety disorders on the chronic physical health conditions of men from a national sample. Am. J. Men's Health 2013, 7, 58S-67S.

[9] Assari, S. Unequal gain of equal resources across racial groups. Int. J. Health Policy Manag. 2017, 6, doi: 10.15171/ijhpm.2017.90.

[10] Assari, S. Health Disparities Due to Minorities Diminished Return: Policy Solutions. Soc. Issues Policy Rev. 2018, 12, 112-45, doi: 10.1111/sipr.12042.

[11] Alaimo, K.; Olson, C. M.; Frongillo, Jr. E. A.; Briefel, R. R. Food insufficiency, family income, and health in US preschool and school-aged children. Am. J. Public Health. 2001, 91, 781.

[12] Shah, C. P.; Kahan, M.; Krauser, J. The health of children of low-income families. CMAJ: Can. Med. Assoc. J. 1987, 137, 485.

[13] Chen, E. Why socioeconomic status affects the health of children: a psychosocial perspective. Curr. Dir. Psychol. Sci. 2004, 13, 112-115.

[14] Hummer, R. A.; Lariscy, J. T. Educational attainment and adult mortality. International Handbook of Adult Mortality. Springer: Berlin, Germany; 2011, pp 241-261.

[15] Assari, S. Combined Racial and Gender Differences in the Long-Term Predictive Role of Education on Depressive Symptoms and Chronic Medical Conditions. J. Racial Ethn. Health Disparities 2016, doi: 10.1007/s40615-016-0239-7.

[16] Assari, S. Ethnic and Gender Differences in Additive Effects of Socio-economics, Psychiatric Disorders, and Subjective Religiosity on Suicidal Ideation among Blacks. Int. J. Prev. Med. 2015, 6, doi: 10.4103/2008-7802.158913.

[17] Hayward, M. D.; Hummer, R. A.; Sasson, I. Trends and group differences in the association between educational attainment and US adult mortality: implications for understanding education's causal influence. Soc. Sci. Med. 2015, 127, 8-18.

[18] Assari, S.; Lankarani, M. M. Race and Urbanity Alter the Protective Effect of Education but not Income on Mortality. Front Public Health 2016, 4, doi: 10.3389/fpubh.2016.00100.
[19] Backlund, E.; Sorlie, P. D.; Johnson, N. J. A comparison of the relationships of education and income with mortality: The National Longitudinal Mortality Study. Soc. Sci. Med. 1999, 49, 1373-1384.

[20] Everett, B. G.; Rehkopf, D. H.; Rogers, R. G. The Nonlinear Relationship between Education and Mortality: An Examination of Cohort, Race/Ethnic, and Gender Differences. Popul. Res. Policy Rev. 2013, 32, 893-917.

[21] Fuller-Rowell, T. E.; Doan, S. N. The social costs of academic success across ethnic groups. Child Dev. 2010, 81, 1696-1713, doi: 10.1111/j.1467-8624.2010.01504.x.

[22] Fuller-Rowell, T. E.; Curtis, D. S.; Doan, S. N.; Coe, C. L. Racial disparities in the health benefits of educational attainment: A study of inflammatory trajectories among African American and white adults. Psychosom. Med. 2015, 77 , 33-40, doi: 10.1097/PSY.0000000000000128.

[23] Hudson, D. L.; Bullard, K. M.; Neighbors, H. W.; Geronimus, A. T.; Yang, J.; Jackson, J. S. Are benefits conferred with greater socioeconomic position undermined by racial discrimination among African American men? J. Mens Health 2012, 9, 127-136.

[24] Assari, S.; Caldwell, C. H. High Risk of Depression in High-Income African American Boys. J. Racial Ethn. Health Disparities 2017, doi: 10.1007/s40615-017-0426-1

[25] Phelan, J. C.; Link, B. G.; Tehranifar, P. Social conditions as fundamental causes of health inequalities: Theory, evidence, and policy implications. J. Health Soc. Behav. 2010, 51, S28S40.

[26] Link, B. G.; Phelan, J. Social conditions as fundamental causes of health inequalities. Handbook Med. Sociol. 2010, 2010, 3-17.

[27] Link, B.; Phelan, J. Social conditions as fundamental causes of disease. J. Health Soc. Behav. 1995, 36, 80-94.

[28] Assari, S. Socioeconomic Determinants of Systolic Blood Pressure; Minorities' Diminished Returns. Journal of Health Economics and Development, 2019; 1 (1): 1-11.

[29] Assari, S.; Nikahd, A.; Malekahmadi, M. R.; Lankarani, M. M.; Zamanian, H. Race by Gender Group Differences in the Protective Effects of Socioeconomic Factors Against Sustained Health Problems Across Five Domains. J. Racial Ethn. Health Disparities 2016, doi: 10.1007/s40615-016-0291-3.

[30] Hudson, D. L. Race, socioeconomic position and depression: The mental health costs of upward mobility. Doctoral Dissertation: The University of Michigan, Ann Arbor, MI, 2009.

[31] Keil, J. E.; Sutherland, S. E.; Knapp, R. G.; Tyroler, H. A. Does equal socioeconomic status in black and white men mean equal risk of mortality? Am. J. Public Health 1992, 82, 1133-1136.

[32] Cooper, R. S. Health and the social status of blacks in the United States. Ann. Epidemiol. 1993, 3, 137-144.

[33] Williams, D. R.; Collins, C. Racial residential segregation: A fundamental cause of racial disparities in health. Public Health Rep. 2001, 116, 404-416.

[34] Williams, D. R.; Yu, Y.; Jackson, J. S.; Anderson, N. B. Racial differences in physical and mental health: Socio-economic status, stress and discrimination. J. Health Psychol. 1997, 2, 335-351. 
[35] Williams, D. R.; Neighbors, H. W.; Jackson, J. S. Racial/ethnic discrimination and health: findings from community studies. Am. J. Public Health 2003, 93, 200-208.

[36] Brunello, G.; Fort, M.; Schneeweis, N.; Winter - Ebmer, R. The causal effect of education on health: What is the role of health behaviors? Health Econ. 2015. doi: 10.1002/hec.3141.

[37] Assari, S.; Lankarani, M. M. Education and Alcohol Consumption among Older Americans; Black-White Differences. Front Public Health 2016, 4, 67. doi: 10.3389/fpubh.2016.00067.

[38] Juhn, Y. J.; Beebe, T. J.; Finnie, D. M.; Sloan, J.; Wheeler, P. H.; Yawn, B.; Williams, A. R. Development and initial testing of a new socioeconomic status measure based on housing data. $J$. Urban Health. 2011, 88, 933-944. doi: 10.1007/s11524-011-9572-7.

[39] Ross, C. E.; Wu, C. L. The links between education and health. Am. Social. Rev. 1995, 719-745.

[40] Montez, J. K.; Hummer, R. A.; Hayward, M. D. Educational attainment and adult mortality in the United States: a systematic analysis of functional form. Demography. 2012, 49, 315-336.

[41] Tyson, K.; Darity, Jr. W.; Castellino, D. R. It's not "a black thing": Understanding the burden of acting white and other dilemmas of high achievement. Am. Sociol. Rev. 2005, 70, 582605 .

[42] Neighbors, H. W.; Njai, R.; Jackson, J. S. Race, ethnicity, John Henryism, and depressive symptoms: The national survey of American life adult reinterview. Res. Human Dev. 2007, 4, 7187.

[43] Montez, J. K.; Hummer, R. A.; Hayward, M. D.; Woo, H.; Rogers, R. G. Trends in the educational gradient of US adult mortality from 1986 through 2006 by race, gender, and age group. Res Aging 2011, 33, 145-171.

[44] Blumberg, S. J.; Foster, E. B.; Frasier, A. M.; Satorius, J.; Skalland, B. J.; Nysse-Carris, K. L.; Morrison, H. M.; Chowdhury, S. R.; Connor, K. S. Design and operation of the National Survey of Children's Health, 2007. Vital Health Stat. 2012, 55, 1-149.

[45] van Dyck, P.; Kogan, M. D.; Heppel, D.; Blumberg, S. J.; Cynamon, M. L.; Newacheck, P. W. The National Survey of Children's Health: A new data resource. Matern Child Health J. 2004, 8, 183-188.

[46] Bramlett, M. D.; Blumberg, S. J. Family structure and children's physical and mental health. Health Aff. 2007, 26, 549-558.

[47] Wallace, S. P.; Padilla-Frausto, D. I.; Smith, S. E. Older adults need twice the federal poverty level to make ends meet in California. Policy Brief UCLA Cent Health Policy Res. 2010, 8, $1-8$.

[48] National Survey of Children's Health. Available online: CATI Instrument

ftp://ftp.cdc.gov/pub/health_statistics/nchs/slaits/nsch07/1a_S urvey_Instrument_English/NSCH_Questionnaire_052109.pdf (access on 1st 6 2019).

[49] Spencer, E. A.; Appleby, P. N.; Davey, G. K.; Key, T. J. Validity of self-reported height and weight in 4808 EPIC-Oxford participants. Public Health Nutr. 2002, 5, 561-565, doi:

\subsection{9/PHN2001322.}

[50] Stewart, A. L. The reliability and validity of self-reported weight and height. J. Chronic Dis. 1982, 35, 295-309, doi: 10.1016/0021-9681(82)90085-6.

[51] Taylor, A. W.; Dal Grande, E.; Gill, T. K.; Chittleborough, C. R.; Wilson, D. H.; Adams, R. J. How valid are self-reported height and weight? A comparison between CATI self-report and clinic measurements using a large cohort study. Aust. N. Z. J. Public Health 2006, 30, 238-246.

[52] Lang, I. A.; Kipping, R. R.; Jago, R.; Lawlor, D. A. Variation in childhood and adolescent obesity prevalence defined by international and country-specific criteria in England and the United States. Eur. J. Clin. Nutr. 2011, 65, 143-150.

[53] Dumith, S. C.; FariasJúnior, J. C. Overweight and obesity in children and adolescents: Comparison of three classification criteria based on body mass index. Rev. Panam. Salud Publ. 2010, 28, 30-35.

[54] Valerio, M. A.; Andreski, P. M.; Schoeni, R. F.; McGonagle, K. A. Examining the association between childhood asthma and parent and grandparent asthma status: implications for practice. Clin. Pediatr. 2010, 49, 535-541. doi: 10.1177/0009922809356465.

[55] Bhan, N.; Glymour, M. M.; Kawachi, I.; Subramanian, S. V. Childhood adversity and asthma prevalence: Evidence from 10 US states (2009-2011). BMJ Open Respir Res. 2014, doi: 10.1136/bmjresp-2013-000016.

[56] Assari, S.; Caldwell, C. H.; Mincy, R. Family Socioeconomic Status at Birth and Youth Impulsivity at Age 15; Blacks' Diminished Return. Children 2018, 5. doi: 10.3390/children5050058.

[57] Assari, S. Parental Education Better Helps White than Black Families Escape Poverty: National Survey of Children's Health. Economies 2018, 6, 30, doi: 10.3390/economies6020030.

[58] Assari, S.; Thomas, A.; Caldwell, C. H.; Mincy, R. B. Blacks' Diminished Health Return of Family Structure and Socioeconomic Status; 15 Years of Follow-up of a National Urban Sample of Youth. J. Urban Health 2018, 95, 21-35, doi: 10.1007/s11524-017-0217-3.

[59] Adler, N. E.; Stewart, J. Reducing obesity: motivating action while not blaming the victim. Milbank Q. 2009, 87, 49-70, doi: 10.1111/j.1468-0009.2009.00547.

[60] Marmot, M.; Allen, J. J. Social determinants of health equity. Am. J. Public Health 2014, doi: 10.2105/AJPH.2014.302200.

[61] Sobal, J; Stunkard, A. J. Socioeconomic status and obesity: A review of the literature. Psychol. Bull. 1989, 105, 260-75.

[62] McLaren, L. Socioeconomic status and obesity. Epidemiol. Rev. 2007, 29, 29-48.

[63] Ben-Shlomo, Y.; Kuh, D. A life course approach to chronic disease epidemiology: conceptual models, empirical challenges and interdisciplinary perspectives. Int. J. Epidemiol. 2002, 31, 285-293.

[64] Ogden, C. L.; Lamb, M. M.; Carroll, M. D.; Flegal, K. M. Obesity and socioeconomic status in adults: United States 1988-1994 and 2005-2008. NCHS data brief no 50. Hyattsville, MD: National Center for Health Statistics. 2010 . 
[65] Lynch J; Smith GD. A life course approach to chronic disease epidemiology. Ann. Rev. Public Health 2005, 26, 1-35.

[66] Assari, S. Life Expectancy Gain Due to Employment Status Depends on Race, Gender, Education, and Their Intersections. J. Racial Ethn. Health Disparities 2017, doi: 10.1007/s40615-017-0381-x.

[67] Assari, S.; Caldwell, C. H. Neighborhood Safety and Major Depressive Disorder in a National Sample of Black Youth; Gender by Ethnic Differences. Children 2017, 4, doi: 10.3390/children4020014.

[68] Assari, S. Whites but Not Blacks Gain Life Expectancy from Social Contacts. Behav. Sci. 2017, 7, doi: 10.3390/bs7040068.

[69] Assari, S. The link between mental health and obesity: Role of individual and contextual factors. Int. J. Prev. Med. 2014, 5, 247-249.

[70] Brunello, G.; Fort, M.; Schneeweis, N.; Winter-Ebmer, R. The Causal Effect of Education on Health: What is the Role of Health Behaviors? Health Econ. 2016, 25, 314-336. doi: 10.1002/hec.3141.

[71] Andresen, E. M.; Malmgren, J. A.; Carter, W. B.; Patrick, D. L. Screening for depression in well older adults: evaluation of a short form of the CES-D (Center for Epidemiologic Studies Depression Scale). Am. J. Prev. Med. 1994, 10, 77-84.

[72] Antonakis, J.; Bendahan, S.; Jacquart, P.; Lalive, R. On making causal claims: A review and recommendations. Leadersh. $Q$. 2010, 21, 1086-1120.

[73] Dawid, A. P.; Faigman, D. L.; Fienberg, S. E. Fitting science into legal contexts: assessing effects of causes or causes of effects? Sociol. Methods Res. 2014, 43, 359-390.

[74] Hudson, D. L.; Neighbors, H. W.; Geronimus, A. T.; Jackson, J. S. The relationship between socioeconomic position and depression among a US nationally representative sample of African Americans. Soc. Psychiatry Psychiatr. Epidemiol. 2012, 47, 373-381, doi: 10.1007/s00127-011-0348-x.

[75] Assari S. Parental Educational Attainment and Academic Performance of American College Students; Blacks' Diminished Returns. Journal of Health Economics and Development, 2019; 1 (1): 21-31.

[76] Barreca, A. I.; Guldi, M.; Lindo, J. M.; Waddell, G. R. Saving babies? Revisiting the effect of very low birth weight classification. Q. J. Econ. 2011, 126, 2117-2223.

[77] Case, A.; Darren L.; Christina P. Economic Status and Health in Childhood: The Origins of the Gradient. Am. Econ. Rev. 2002, 92, 1308-1334m doi: 10.1257/000282802762024520.

[78] Victorino, C. C.; Gauthier, A. H. The social determinants of child health: variations across health outcomes - a population-based cross-sectional analysis. BMC Pediatr. 2009, 9, 53. doi: 10.1186/1471-2431-9-53.

[79] Smith, L. A.; Hatcher-Ross, J. L.; Wertheimer, R.; Kahn, R. S. Rethinking race/ethnicity, income; and childhood asthma: racial/ethnic disparities concentrated among the very poor. Public Health Rep. 2005, 120, 109-116.

[80] Pearlman, D. N.; Zierler, S.; Meersman, S.; Kim, H. K.; Viner-Brown, S. I.; Caron, C. Race disparities in childhood asthma: does where you live matter? J. Natl. Med. Assoc. 2006, 98, 239-247.
[81] Thakur, N.; Oh, S. S.; Nguyen, E. A.; Martin, M.; Roth, L. A.; Galanter, J.; Gignoux, C. R.; Eng, C.; Davis, A.; Meade, K.; et al. Socioeconomic status and childhood asthma in urban minority youths. The GALA II and SAGE II studies. Am. J. Respir. Crit. Care Med. 2013, 188, 1202-1209. doi: 10.1164/rccm.201306-1016OC.

[82] Carroll, K. Socioeconomic status, race/ethnicity, and asthma in youth. Am. J. Respir. Crit. Care Med. 2013, 188, 1180-1181. doi: 10.1164/rccm.201310-1768ED.

[83] Feagin, J. R. Excluding blacks and others from housing: The foundation of white racism. Cityscape, 1999, 79-91.

[84] Johnson, J. H.; Parnell, A.; Joyner, A. M.; Christman, C. J.; Marsh, B. Racial apartheid in a small North Carolina town. Rev. Black Political Econ. 2004, 31, 89-107.

[85] Bass, S. Policing space, policing race: Social control imperatives and police discretionary decisions. Soc. Justice 2001, 28, 156-176.

[86] Goldberg, D. T. The new segregation. Race Soc. 1998, 1, 1532.

[87] Sewell, A. A.; Jefferson, K. A.; Lee, H. Living under surveillance: Gender, psychological distress, and stop-question-and-frisk policing in New York City. Soc. Sci. Med. 2016, 159, 1-13.

[88] Pearce, D. M. Gatekeepers and homeseekers: Institutional patterns in racial steering. Soc. Probl. 1979, 26, 325-342.

[89] Sewell, A. A. Opening the Black Box of Segregation. Race Real Estate 2015, 87.

[90] Burley, D. White racial reasoning: Rational racism in the perceptions of white males. Hum. Soc. 2005. 29, 116-125.

[91] Norton, M. I.; Sommers, S. R. Whites see racism as a zero-sum game that they are now losing. Perspect. Psychol. Sci. 2011, 6, 215-218.

[92] Chang, R. S. Reverse Racism: Affirmative Action, the Family, and the Dream that is America. Hastings Const. LQ. 1995, 23, 1115 .

[93] Assari, S.; Caldwell, C. H.; Mincy, R. B. Maternal Educational Attainment at Birth Promotes Future Self-Rated Health of White but Not Black Youth: A 15-Year Cohort of a National Sample. J. Clin. Med. 2018, doi: 10.3390/jcm7050093.

[94] Assari, S. Diminished Economic Return of Socioeconomic Status for Black Families. Soc. Sci. 2018, 7, 74, doi: 10.3390/socsci7050074.

[95] Assari, S. Socioeconomic Status and Self-Rated Oral Health; Diminished Return among Hispanic Whites. Dent. J. 2018, 6, doi: $10.3390 / \mathrm{dj} 6020011$.

[96] Assari, S. High Income Protects Whites but Not African Americans against Risk of Depression. Healthcare 2018, 6, doi: $10.3390 /$ healthcare6020037.

[97] Assari, S.; Mistry, R. Educational Attainment and Smoking Status in a National Sample of American Adults; Evidence for the Blacks' Diminished Return. Int. J. Environ. Res. Public Health 2018, 15, doi: 10.3390/ijerph15040763.

[98] Jones, R. K.; Luo, Y. The culture of poverty and African-American culture: An empirical assessment. Sociol. Perspect. 1999, 42, 439-458. 
[99] Scholtens, S.; Wijga, A. H.; Seidell, J. C.; Brunekreef, B.; de Jongste, J. C.; Gehring, U.; Smit, H. A. Overweight and changes in weight status during childhood in relation to asthma symptoms at 8 years of age. J. Allergy Clin. Immunol. 2009, $123,1312-1318$.

[100] Farber, H. J.; Knowles, S. B.; Brown, N. L.; Caine, L.; Luna, V.; Qian, Y.; Lavori, P.; Wilson, S. R. Secondhand tobacco smoke in children with asthma: sources of and parental perceptions about exposure in children and parental readiness to change. Chest 2008, 133, 1367-1374, doi: 10.1378/chest.07-2369.

[101] Kamil F, Pinzon I, Foreman MG. Sex and race factors in early-onset COPD. Curr Opin Pulm Med. 2013 Mar; 19 (2): 140-4. doi: 10.1097/MCP.0b013e32835d903b. Review. PubMed PMID: 23361195; PubMed Central PMCID: PMC3976899.

[102] Gjerdevik, M., Grydeland, T. B., Washko, G. R., Coxson, H. O., Silverman, E. K., Gulsvik, A., \& Bakke, P. S. (2015). The relationship of educational attainment with pulmonary emphysema and airway wall thickness. Annals of the American Thoracic Society, 12 (6), 813-820.

[103] Centers for Disease Control and Prevention (CDC. (2007). Prevalence of self-reported cardiovascular disease among persons aged $>$ or $=35$ years with diabetes--United States, 1997-2005. MMWR. Morbidity and mortality week ly report, $56(43), 1129$.

[104] Assari S. Number of Chronic Medical Conditions Fully Mediates the Effects of Race on Mortality; 25-Year Follow-Up of a Nationally Representative Sample of Americans. J Racial Ethn Health Disparities. 2017 Aug; 4 (4): 623-631. doi: 10.1007/s40615-016-0266-4. Epub 2016 Jul 20. PubMed PMID: 27440120; PubMed Central PMCID: PMC6662183.

[105] Assari, S. Socioeconomic Determinants of Systolic Blood Pressure; Minorities' Diminished Returns. Journal of health economics and development, 2019, l (1), 1.

[106] Assari, S.; Bazargan, M. Educational Attainment Better Reduces Disability for Non-Hispanic than Hispanic Americans. Eur. J. Investig. Health Psychol. Educ. 2020, 10, 10-17.

[107] Assari S, Caldwell CH, Mincy R. Family Socioeconomic Status at Birth and Youth Impulsivity at Age 15; Blacks' Diminished Return. Children (Basel). 2018 May 1; 5 (5). pii: E58. doi: 10.3390/children5050058. PubMed PMID: 29724004; PubMed Central PMCID: PMC5977040.

[108] Assari S, Caldwell CH, Mincy RB. Maternal Educational Attainment at Birth Promotes Future Self-Rated Health of White but Not Black Youth: A 15-Year Cohort of a National Sample. J Clin Med. 2018 May 1; 7 (5). pii: E93. doi: 10.3390/jcm7050093. PubMed PMID: 29723957; PubMed Central PMCID: PMC5977132.
[109] Assari S, Thomas A, Caldwell CH, Mincy RB. Blacks' Diminished Health Return of Family Structure and Socioeconomic Status; 15 Years of Follow-up of a National Urban Sample of Youth. J Urban Health. 2018 Feb; 95 (1): 21-35. doi: 10.1007/s11524-017-0217-3. PubMed PMID: 29230628; PubMed Central PMCID: PMC5862702.

[110] Assari S, Caldwell CH. Family Income at Birth and Risk of Attention Deficit Hyperactivity Disorder at Age 15: Racial Differences. Children (Basel). 2019 Jan 14; 6 (1). pii: E10. doi: 10.3390/children6010010. PubMed PMID: 30646634; PubMed Central PMCID: PMC6352113.

[111] Assari S. Does School Racial Composition Explain Why High Income Black Youth Perceive More Discrimination? A Gender Analysis. Brain Sci. 2018 Jul 30; 8 (8). pii: E140. doi: 10.3390/brainsci8080140. PubMed PMID: 30061476; PubMed Central PMCID: PMC6119879.

[112] Assari S, Moghani Lankarani M. Workplace Racial Composition Explains High Perceived Discrimination of High Socioeconomic Status African American Men. Brain Sci. 2018 Jul 27; 8 (8). pii: E139. doi: 10.3390/brainsci8080139. PubMed PMID: 30060492; PubMed Central PMCID: PMC6120025.

[113] Assari S, Gibbons FX, Simons R. Depression among Black Youth; Interaction of Class and Place. Brain Sci. 2018 Jun 12; 8 (6). pii: E108. doi: 10.3390/brainsci8060108. PubMed PMID: 29895752; PubMed Central PMCID: PMC6025590.

[114] Assari S, Gibbons FX, Simons RL. Perceived Discrimination among Black Youth: An 18-Year Longitudinal Study. Behav Sci (Basel). 2018 Apr 27; 8 (5). pii: E44. doi: 10.3390/bs8050044. PubMed PMID: 29702587; PubMed Central PMCID: PMC5981238.

[115] Assari S, Lankarani MM, Caldwell CH. Does Discrimination Explain High Risk of Depression among High-Income African American Men? Behav Sci (Basel). 2018 Apr 19; 8 (4). pii: E40. doi: 10.3390/bs8040040. PubMed PMID: 29671796; PubMed Central PMCID: PMC5946099.

[116] Assari S, Preiser B, Lankarani MM, Caldwell CH. Subjective Socioeconomic Status Moderates the Association between Discrimination and Depression in African American Youth. Brain Sci. 2018 Apr 20; 8 (4). pii: E71. doi: 10.3390/brainsci8040071. PubMed PMID: 29677115; PubMed Central PMCID: PMC5924407.

[117] Assari S, Caldwell CH. Social Determinants of Perceived Discrimination among Black Youth: Intersection of Ethnicity and Gender. Children (Basel). 2018 Feb 15; 5 (2). pii: E24. doi: 10.3390/children5020024. PubMed PMID: 29462893; PubMed Central PMCID: PMC5835993. 